\title{
Oxidative stress during early pregnancy and birth outcomes
}

\author{
Lisha Shastri ${ }^{1}$, Rajkumar S Pammal ${ }^{2}$, Indu Mani ${ }^{3}$, Tinku Thomas ${ }^{4}$ and Anura V Kurpad ${ }^{3,5, *}$ \\ ${ }^{1}$ St. John's Medical College, Bangalore, India: ${ }^{2}$ Harvard College, Cambridge, MA, USA: ${ }^{3}$ Division of Nutrition, \\ St. John's Research Institute, St. John's National Academy of Health Sciences, Bangalore, India: ${ }^{4}$ Division of \\ Epidemiology and Biostatistics, St. John's Research Institute, St. John's National Academy of Health Sciences, \\ Bangalore, India: ${ }^{5}$ Department of Physiology, St. John's Medical College and Research Institute, Koramangala, \\ Bangalore 560034, India
}

Submitted 1 October 2015: Final revision received 14 April 2016: Accepted 20 April 2016: First published online 3 June 2016

\begin{abstract}
Objective: Routine high-dose Fe supplementation in non-anaemic pregnant women may induce oxidative stress and eventually affect birth outcomes. The aim of the present study was to measure oxidative stress markers in pregnant women with low/normal and high $\mathrm{Hb}$ values in trimester $1\left(\mathrm{Hb}_{1}\right)$ and to relate these to birth weight. Design: A cross-sectional study where selected oxidative stress markers were analysed in both maternal (trimester 1; T1) and cord blood samples and correlated with birth weight.

Setting: A tertiary hospital in urban South India.

Subjects: One hundred women were chosen based on their $\mathrm{Hb}_{1}$ values (forty women with low/normal $\mathrm{Hb}_{1}(<110 \mathrm{~g} / \mathrm{l})$ and sixty women with high $\left.\mathrm{Hb}_{1}(\geq 120 \mathrm{~g} / \mathrm{l})\right)$. Results: In $\mathrm{T} 1$, women with high $\mathrm{Hb}_{1}$ values were found to have lower paraoxonase-1 (PON-1) activity (424.7 (SD 163.7) v. 532.9 (SD 144.7) pmol $p$-nitrophenol formed/min per $\mathrm{ml}$ plasma, $P=0.002)$ and higher lipid peroxides compared with women with low/normal $\mathrm{Hb}_{1}$. Routine supplementation of $\mathrm{Fe}$ to these women resulted in persistent lower PON-1 activity in cord blood $(P=0.02)$ and directionally lower $(P=0 \cdot 142)$ birth weights. Furthermore, women with high $\mathrm{Hb}_{1}$ who delivered low-birth-weight babies were observed to have lowest PON-1 activity in T1. No changes were observed in other markers (myeloperoxidase activity and total antioxidant levels).

Conclusions: Routine Fe supplementation in pregnant women with high $\mathrm{Hb}_{1}$ associated with increased oxidative stress, as reflected by low PON-1 activity in T1, could potentially lead to deleterious effects on birth weight.
\end{abstract}

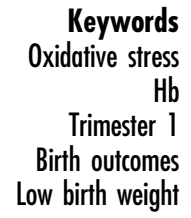

Fe deficiency is the most common nutritional disorder in the world and is often the cause of anaemia, a frequently encountered haematological problem in pregnancy care. Currently, the national policy in India is to provide universal supplementation equivalent to $100 \mathrm{mg}$ elemental $\mathrm{Fe} / \mathrm{d}$ to all pregnant women, regardless of their initial $\mathrm{Fe} / \mathrm{Hb}$ status ${ }^{(1)}$.

A number of recent studies suggest that Fe provided in excess may induce oxidative stress through the production of reactive oxygen species. Supplementation of $100 \mathrm{mg}$ $\mathrm{Fe} / \mathrm{d}$ to mildly anaemic women resulted in an increase in oxidative stress $^{(2)}$, while a dose of $50 \mathrm{mg} / \mathrm{d}$ given in the second trimester to pregnant women with high $\mathrm{Hb}$ $(\geq 135 \mathrm{~g} / \mathrm{l})$ resulted in a higher number of babies born small for gestational age and a higher incidence of hypertensive disorders ${ }^{(3)}$. Intra-uterine oxidative stress is associated with adverse birth outcomes such as intrauterine growth restriction, pre-eclampsia and an elevated risk of premature rupture of membranes ${ }^{(4)}$, as well as an elevated risk of metabolic syndrome in later life ${ }^{(5)}$.
An earlier Indian study showed that women with high $\mathrm{Hb}$ values in trimester 1 (T1), who consumed the recommended dose of supplemental Fe during pregnancy, had a higher risk of delivering a term low-birth-weight (LBW) baby ${ }^{(6)}$.

The standard marker of oxidative stress is the level of lipid peroxides (LPO) formed from unsaturated lipids, mainly from oxidized LDL. One of the key enzymes that protects LDL from oxidation is paraoxonase-1 (PON-1). Studies have shown that decreased serum PON-1 and increased LPO may be indices of oxidative stress leading to early pathogenesis of atherosclerotic heart disease in pregnant women ${ }^{(7)}$. Another enzyme that is involved in the oxidative modification of lipoproteins, as well as in inflammation, is myeloperoxidase (MPO). Increased MPO activity has been reported in pregnant women with pre-eclampsia and intra-uterine growth restriction ${ }^{(8)}$.

The assessment of oxidative stress in the current study was therefore based on measurement of the enzymatic 
activities of PON-1, LPO, MPO and total antioxidants (ToAx). The purpose of the current study was to assess if $\mathrm{Hb}$ status in $\mathrm{T} 1\left(\mathrm{Hb}_{1}\right)$ was associated with oxidative stress and if this could be related to birth outcomes.

\section{Participants and methods}

The current study was part of a prospective observational cohort of pregnant women conducted at St. John's Research Institute and St. John's Medical College Hospital in Bangalore, India. The details of the cohort have been described previously ${ }^{(6,9)}$. Briefly, the cohort consisted of 1838 pregnant women in the age group 17-40 years, who had no known morbidities and who delivered live babies at St. John's Medical College Hospital. All women of this cohort received routine Fe supplementation of $45 \mathrm{mg} / \mathrm{d}$, although only 642 women could be considered anaemic in $\mathrm{T} 1\left(\mathrm{Hb}_{1}<110 \mathrm{~g} / \mathrm{l}\right)$. From this cohort, 100 participants were chosen based on their $\mathrm{Hb}_{1}$ values: forty with $\mathrm{Hb}_{1}<110 \mathrm{~g} / \mathrm{l}$ and sixty with $\mathrm{Hb}_{1} \geq 120 \mathrm{~g} / \mathrm{l}$. All participants were supplemented with $45 \mathrm{mg}$ elemental $\mathrm{Fe} / \mathrm{d}$ in trimesters 2 and $3^{(6)}$. The study by Genc et al. ${ }^{(10)}$ reported a difference of $40 \mathrm{U} / \mathrm{ml}$ in PON-1 between pre-eclampsia and normal pregnancy. To observe this difference between the low/normal and high $\mathrm{Hb}_{1}$ groups, with $5 \%$ level of significance and $80 \%$ power, the sample size required was forty-five per group. We could get valid data in only forty low/normal $\mathrm{Hb}_{1}$ women. To improve the power, we increased the number in the high $\mathrm{Hb}_{1}$ group to sixty.

\section{Blood sample collection and analysis}

Venous whole blood samples were collected into EDTAcoated anticoagulant tubes (Becton Dickenson, NJ, USA) by trained laboratory assistants at T1 (11.9 (sD 2.3) weeks of gestation) and cord blood (CB) samples were collected at birth. $\mathrm{Hb}$ concentration was analysed using an automated cyanmethaemoglobin technique (ABX Pentra 60 C+ haematology analyser; Horiba ABX Diagnostics, Germany). The measuring range was $80-180 \mathrm{~g} / \mathrm{l}$ with a within-run precision of $>99 \%$.

\section{Analysis of oxidative stress parameters}

The arylesterase activity of PON-1 was assayed using p-nitrophenyl acetate as the substrate as described by Burlina et $a l^{(11)}$. Briefly, the rate of formation of $p$-nitrophenol was measured at $405 \mathrm{~nm}$ and arylesterase activity was expressed as $\mathrm{pmol} p$-nitrophenol generated $/ \mathrm{min}$ per ml plasma. MPO was measured as the rate of oxidation of o-dianisidine in the presence of $\mathrm{H}_{2} \mathrm{O}_{2}$ at $450 \mathrm{~nm}^{(12)}$. Enzyme activity was expressed as $\mathrm{U} / \mathrm{min}$ per $\mathrm{ml}$ plasma ( $1 \mathrm{U}=1$ OD change at $450 \mathrm{~nm}$ ). LPO were measured as mmol thiobarbituric acid-reactive species formed on reaction of plasma with malondialdehyde. Briefly, plasma proteins were first precipitated with $15 \%(\mathrm{w} / \mathrm{v})$ TCA and the supernatant was reacted with 20-mм thiobarbituric acid in the presence of $10 \%(\mathrm{w} / \mathrm{v}) \mathrm{SDS}$. The thiobarbituric acid-reactive species formed were measured in a fluorescence spectrophotometer with $\lambda_{\mathrm{ex}}=520 \mathrm{~nm}$ and $\lambda_{\mathrm{em}}=570 \mathrm{~nm}$, and data were expressed as nmol malondialdehyde/ml plasma. ToAx were measured using the TEAC method (Trolox equivalent antioxidant capacity) based on the suppression of absorbance of the radical cation of 2,2'-azinobis(3-ethyl benzothiazoline sulfonate) by plasma antioxidants ${ }^{(13)}$ and were expressed as nmol Trolox equivalent/ml plasma.

\section{Delivery and birth information}

Infants were weighed to the nearest $10 \mathrm{~g}$ on an electronic weighing scale (Salter Housewares 914 Electronic Baby and Toddler Scale, NY, USA) immediately after birth. LBW was defined as birth weight less than $2500 \mathrm{~g}$ irrespective of gestational age.

\section{Statistical analysis}

The comparison of the oxidative stress markers among the different groups of $\mathrm{Hb}_{1}$ was performed using the independent-sample $t$ test or the Mann-Whitney $U$ test if not normally distributed. The data were also analysed based on dividing the participants into two groups based on birth outcome (LBW and others). Normally distributed data are presented as mean and standard deviation and the rest as median (quartile 1-quartile 3). For all analyses, two-sided $P$ values $<0.05$ were considered statistically significant. The oxidative stress markers were compared between four combined groups of low/normal and high $\mathrm{Hb}_{1}$ and low and normal birth weight using one-way ANOVA. All statistical analyses were performed using the statistical software package IBM SPSS Statistics for Windows, Version 18.0.

\section{Results}

The general characteristics and birth details of the women participating in the study (total, low/normal $\mathrm{Hb}_{1}$ and high $\mathrm{Hb}_{1}$ ) are summarized in Table 1 . There were no differences in characteristics between the two groups except their $\mathrm{Hb}_{1}$ values. Mean compliance to Fe supplementation was about $70 \%$ among all women. Among the women who had low/normal $\mathrm{Hb}_{1}, 25 \%$ of babies were born $\mathrm{LBW}$, whereas $38 \%$ of women with high $\mathrm{Hb}_{1}$ gave birth to LBW babies.

Table 2 describes the results of oxidative stress parameters in women with low/normal $v$. high $\mathrm{Hb}_{1}$. PON-1 showed a significantly lower activity in T1 in the high $\mathrm{Hb}_{1}$ group (424.7 (sD 163.7) pmol p-nitrophenol formed/min per ml plasma) compared with the low/ normal $\mathrm{Hb}_{1}$ group (532.9 (sD 144.7) pmol $p$-nitrophenol formed/min per $\mathrm{ml}$ plasma, $P=0 \cdot 002)$. The same trend held for PON-1 in CB samples $(P=0 \cdot 020)$. The high $\mathrm{Hb}_{1}$ 
Table 1 General characteristics of the study population ( $n$ 100): pregnant women attending a tertiary hospital in urban South India

\begin{tabular}{|c|c|c|c|c|c|c|c|}
\hline & \multicolumn{2}{|c|}{ All } & \multicolumn{2}{|c|}{$\mathrm{Hb}_{1}<110 \mathrm{~g} / \mathrm{l}$} & \multicolumn{2}{|c|}{$\mathrm{Hb}_{1} \geq 120 \mathrm{~g} / \mathrm{l}$} & \multirow[b]{2}{*}{$P$ value* } \\
\hline & Mean & SD & Mean & SD & Mean & SD & \\
\hline Age (years) & 23.9 & 3.2 & 23.3 & $2 \cdot 9$ & 24.4 & $3 \cdot 3$ & 0.076 \\
\hline Height $(\mathrm{cm})$ & 155.6 & 5.4 & $156 \cdot 0$ & $5 \cdot 3$ & $155 \cdot 3$ & $5 \cdot 6$ & 0.555 \\
\hline Weight (kg) & 51.5 & 8.9 & $49 \cdot 8$ & $9 \cdot 1$ & $52 \cdot 6$ & 8.6 & 0.118 \\
\hline Final gestational age (weeks) & 38.6 & 1.4 & 38.7 & 1.4 & 38.5 & 1.4 & 0.361 \\
\hline Birth weight $(\mathrm{g})$ & 2771 & 449 & 2836 & 482 & 2728 & 424 & 0.240 \\
\hline $\mathrm{Hb}_{1}(\mathrm{~g} / \mathrm{l})$ & 119 & 18 & 98 & 7 & 133 & 6 & $<0.001$ \\
\hline Total supplemental Fe intake (mg) & 7329 & 736 & 7392 & 674 & 7288 & 777 & 0.504 \\
\hline LBW $(n)$ & \multirow{2}{*}{\multicolumn{2}{|c|}{$\begin{array}{l}33 \\
33\end{array}$}} & \multirow{2}{*}{\multicolumn{2}{|c|}{$\begin{array}{l}10 \\
25\end{array}$}} & \multirow{2}{*}{\multicolumn{2}{|c|}{$\begin{array}{l}23 \\
38\end{array}$}} & 0.165 \\
\hline$\%$ & & & & & & & \\
\hline
\end{tabular}

$\mathrm{Hb}_{1}, \mathrm{Hb}$ in trimester 1 ; LBW, low birth weight.

${ }^{*}$ Calculated by the independent-sample $t$ test for continuous data and by the $x^{2}$ test for categorical data. $P<0.05$ was considered to be statistically significant.

Table 2 Comparison of oxidative stress markers within groups according to low/normal and high $\mathrm{Hb}$ in the first trimester, among pregnant women attending a tertiary hospital in urban South India

\begin{tabular}{|c|c|c|c|c|c|}
\hline & \multicolumn{2}{|c|}{$\mathrm{Hb}_{1}<110 \mathrm{~g} / \mathrm{l}$} & \multicolumn{2}{|c|}{$\mathrm{Hb}_{1} \geq 120 \mathrm{~g} / \mathrm{l}$} & \multirow[b]{2}{*}{$P$ value ${ }^{*}$} \\
\hline & Mean or median & SD or IQR & Mean or median & SD or IQR & \\
\hline \multicolumn{6}{|l|}{ PON-1 } \\
\hline T1 & 532.9 & 144.7 & 424.7 & $163 \cdot 7$ & 0.002 \\
\hline CB & 361.5 & 138.2 & 302.0 & 101.6 & 0.020 \\
\hline \multicolumn{6}{|l|}{ MPO† } \\
\hline T1 & 3.02 & $1.58-6.23$ & $4 \cdot 12$ & $1.68-5.94$ & 0.623 \\
\hline $\mathrm{CB}$ & $4 \cdot 12$ & $0.98-7.80$ & 2.35 & $0.74-5.36$ & 0.525 \\
\hline \multicolumn{6}{|l|}{ LPO† } \\
\hline $\mathrm{T} 1$ & 0.31 & $0.09-2.33$ & $1 \cdot 20$ & $0.25-2.00$ & 0.046 \\
\hline CB & 0.42 & $0.07-0.79$ & 0.37 & $0.23-0.65$ & 0.981 \\
\hline \multicolumn{6}{|l|}{ ToAx† } \\
\hline T1 & 1.53 & $1.30-2.44$ & 1.47 & $1 \cdot 16-2.44$ & 0.918 \\
\hline $\mathrm{CB}$ & 1.59 & $1.05-2.50$ & 1.34 & $1.09-2.55$ & 0.916 \\
\hline
\end{tabular}

$\mathrm{Hb}_{1}, \mathrm{Hb}$ in T1; IQR, interquartile range (quartile 1-quartile 3); PON-1, paraoxonase-1; T1, trimester 1; CB, cord blood; MPO, myeloperoxidase; LPO, lipid peroxides; ToAx, total antioxidants.

PON-1 expressed as pmol p-nitrophenol formed/min per $\mathrm{ml}$ plasma; MPO expressed as U/min per ml plasma; LPO expressed as nmol malondialdehyde/ml plasma; ToAx expressed as $\mathrm{nmol}$ Trolox equivalent $/ \mathrm{ml}$ plasma.

${ }^{\star} P$ value calculated from the independent-samples $t$ test. $P<0.05$ was considered to be statistically significant.

†Median and IQR with $P$ value calculated from the Mann-Whitney $U$ test. $P<0.05$ was considered to be statistically significant.

group also had a higher mean LPO level in T1 $(P=0 \cdot 046)$ but not in CB. Although not statistically significant, women with high $\mathrm{Hb}_{1}$ had babies with a mean birth weight that was $108 \mathrm{~g}$ less than women with low/normal $\mathrm{Hb}_{1}$ $(P=0 \cdot 240)$. No differences were seen in MPO activity or ToAx levels between the groups.

The participants were further sorted into two additional groups based on birth weight: Group 1, low/normal $\mathrm{Hb}_{1}$ and normal birth weight (NBW); Group 2, low/normal $\mathrm{Hb}_{1}$ and LBW; Group 3, high $\mathrm{Hb}_{1}$ and NBW; and Group 4, high $\mathrm{Hb}_{1}$ and LBW. Among these groups, both $\mathrm{T} 1$ and $\mathrm{CB}$ PON-1 were lower in Group 4 compared with the control Group 1 (Fig. 1), although only the T1 values were statistically significant.

Subsequently, these parameters were also analysed based on a birth weight grouping (Table 3). Women who delivered LBW babies had a significantly lower T1 PON-1 activity compared with those who delivered babies with NBW. The LBW group also had a higher mean LPO level in T1, although this was not significant. No differences were seen in any of the parameters in the CB samples.

\section{Discussion}

Fe-deficiency anaemia is among the commonest problems encountered during pregnancy, especially in developing countries such as India. A routine supplementation of $\mathrm{Fe}$ and folic acid during the second and third trimesters of pregnancy is believed to be essential for the benefit of both the fetus and the mother. However, an increasing number of studies especially from developing countries suggest that high levels of Fe can cause undesirable secondary effects, including gestational diabetes mellitus and pre-eclampsia ${ }^{(5)}$. Epidemiological studies also show negative associations between birth outcomes and both low and high $\mathrm{Hb}$ levels during pregnancy ${ }^{(14,15)}$. However, in India, the current national guideline prescribes 
a universal dosage of $100 \mathrm{mg}$ elemental $\mathrm{Fe} / \mathrm{d}$ during pregnancy $^{(1)}$, despite the possibility of high Fe supplementation leading to adverse outcomes ${ }^{(16,17)}$, especially in women who start out the pregnancy with high $\mathrm{Hb}^{(6)}$.

In the current study, all women were supplemented with $45 \mathrm{mg}$ elemental $\mathrm{Fe} / \mathrm{d}$ during their second and third trimesters of pregnancy, irrespective of their initial $\mathrm{Hb}$ status $^{(6)}$. We have earlier reported that even this dose of $\mathrm{Fe}$ supplementation in pregnant women with a high $\mathrm{Hb}_{1}$ has an adverse impact on birth outcome ${ }^{(6)}$. Similar results have been reported with $50 \mathrm{mg}$ elemental Fe provided daily for 8 weeks during pregnancy ${ }^{(18)}$. Supplementing Fe to

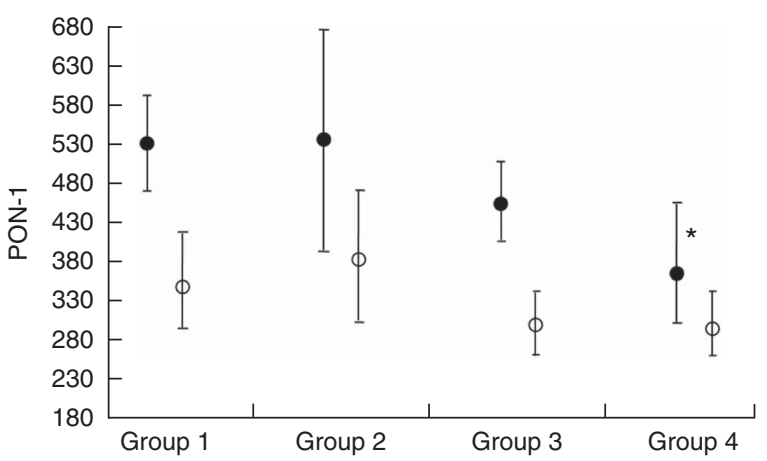

Fig. 1 Mean paraoxonase-1 (PON-1) in the trimester 1 (T1) blood of mothers ( $)$ and the cord blood of babies (O) expressed as pmol $p$-nitrophenol formed/min per $\mathrm{ml}$ plasma. Values are means with their $95 \%$ confidence limits represented by vertical lines. ${ }^{*} P=0.004$ when Group 4 of $\mathrm{T} 1 \mathrm{PON}-1$ is compared with Group 1. All groups were given the routine iron supplementation (Group 1, low/normal $\mathrm{Hb}_{1}$ and normal birth weight; Group 2, low/normal $\mathrm{Hb}_{1}$ and low birth weight; Group 3, high $\mathrm{Hb}_{1}$ and normal birth weight; Group 4, high $\mathrm{Hb}_{1}$ and low birth weight; $\mathrm{Hb}_{1}, \mathrm{Hb}$ in $\mathrm{T} 1$ ) healthy, non-anaemic pregnant women has been reported to increase oxidative stress, resulting in deleterious effects on lipid peroxidation ${ }^{(19,20)}$ as well as protein oxidation ${ }^{(18)}$. Some of these effects have been shown to be ameliorated by the concomitant consumption of antioxidants such as vitamin $C^{(19)}$. In the current study, effects on both lipid peroxidation as well as protein oxidation (using PON-1 activity as a surrogate marker ${ }^{(21)}$ ) were investigated. It was seen that women who started their pregnancy with a high $\mathrm{Hb}_{1}$ actually had a higher level of oxidative stress as evidenced by higher levels of LPO and lower PON-1 activity in T1 (Table 2).

Furthermore, Fig. 1 suggests that women with high $\mathrm{Hb}_{1}$, who eventually delivered babies that were LBW, had further lower PON-1 activity in T1 compared with those who had low/normal $\mathrm{Hb}_{1}$. Considering the fact that all women had similar Fe supplementation during their pregnancy, irrespective of $\mathrm{Hb}_{1}$ values, these data suggest that women with high $\mathrm{Hb}_{1}$ associated with low PON-1 activity may be more susceptible to the possible deleterious effects of this routine Fe supplement. On the other hand, it is important to emphasize that anaemic women appear to have benefited by the Fe supplementation, as evidenced by the higher PON-1 activity in CB as well as NBW.

PON-1 is an important anti-oxidative enzyme associated with HDL which prevents the oxidation of LDL and reduces the formation of atheromatous plaques in the blood vessels. It therefore has a protective role against cellular damage from oxidative stress ${ }^{(22)}$ and low serum PON-1 activity is associated with increased risk of atherosclerosis $^{(7,23)}$ as well as adverse birth outcomes ${ }^{(10,21)}$.

The activity of PON-1 in T1 was significantly lower among women who delivered LBW babies (Table 3).

Table 3 Comparison of oxidative stress markers within groups according to birth weight, among pregnant women attending a tertiary hospital in urban South India

\begin{tabular}{|c|c|c|c|c|c|}
\hline & \multicolumn{2}{|c|}{ NBW } & \multicolumn{2}{|c|}{ LBW } & \multirow[b]{2}{*}{$P$ value } \\
\hline & Mean or median & SD or IQR & Mean or median & SD or IQR & \\
\hline $\mathrm{Hb}_{1}(\mathrm{~g} / \mathrm{l})$ & 118 & 18 & 121 & 18 & 0.373 \\
\hline \multicolumn{5}{|l|}{ PON-1 } & $<0.001$ \\
\hline $\mathrm{T} 1$ & 487.5 & 157.9 & $406 \cdot 3$ & 169.5 & 0.031 \\
\hline CB & 323.4 & $123 \cdot 7$ & $327 \cdot 2$ & 113.5 & 0.884 \\
\hline \multicolumn{6}{|l|}{ MPO† } \\
\hline $\mathrm{T} 1$ & 4.05 & $1.55-5.94$ & 3.43 & $1.84-6.78$ & 0.640 \\
\hline CB & 2.51 & $0.77-6.87$ & 2.62 & $0.64-5.07$ & 0.400 \\
\hline \multicolumn{6}{|l|}{ LPO† } \\
\hline $\mathrm{T} 1$ & 0.51 & $0.12-1.99$ & 1.53 & $0.73-2.53$ & 0.095 \\
\hline CB & 0.39 & $0.19-0.60$ & 0.45 & $0.20-0.88$ & 0.442 \\
\hline \multicolumn{6}{|l|}{ ToAxt } \\
\hline T1 & 1.46 & $1 \cdot 21-2.43$ & 2.05 & $1 \cdot 16-2 \cdot 48$ & 0.887 \\
\hline $\mathrm{CB}$ & 1.36 & $1.09-2.53$ & 1.97 & $1.08-2.57$ & 0.847 \\
\hline
\end{tabular}

NBW, normal birth weight; LBW, low birth weight; IQR, interquartile range (quartile 1-quartile 3); Hb 1 , Hb in T1; PON-1, paraoxonase-1; T1, trimester 1; $\mathrm{CB}$, cord blood; MPO, myeloperoxidase; LPO, lipid peroxides; ToAx, total antioxidants.

PON-1 expressed as pmol $p$-nitrophenol formed/min per $\mathrm{ml}$ plasma; MPO expressed as U/min per $\mathrm{ml}$ plasma; LPO expressed as nmol malondialdehyde/ml plasma; ToAx expressed as nmol Trolox equivalent $/ \mathrm{ml}$ plasma.

${ }^{\star} P$ value calculated from the independent-sample $t$ test. $P<0.05$ was considered to be statistically significant.

†Median and IQR with $P$ value calculated from the Mann-Whitney $U$ test. $P<0.05$ was considered to be statistically significant. 
One explanation for this is that PON-1 is itself very susceptible to oxidative stress and can be inactivated by free-radical-induced oxidation ${ }^{(24)}$. PON-1 activity has been reported to decrease as pregnancy progresses, as it is consumed when stabilizing the oxidative stress levels in the blood ${ }^{(24)}$. In addition to the effects of haemodilution, it has been postulated that the lower levels could be a result of decreased protein synthesis due to cellular injury, which in turn decreases the enzymatic turnover, and thus contributes to the decrease in serum levels of the enzyme ${ }^{(23)}$. Recent studies have shown that LBW babies have low PON-1 levels in $\mathrm{CB}^{(23)}$; however, we did not observe such an effect. This might be due to the fact that the levels of LPO, which are the key influencers of PON-1 activity, were unaffected in the CB of the LBW group.

Studies have shown that increased protein oxidation markers and lowered PON-1 activity in early pregnancy could predict clinical complications like pre-eclampsia and gestational diabetes mellitus ${ }^{(10,21)}$. In combination with the current finding of higher oxidative stress and lower PON-1 activity in $\mathrm{T} 1$ also being associated with high $\mathrm{Hb}_{1}$ as well as LBW, the potential of PON-1 being used as an early marker of gestational morbidities is worth investigating.

MPO is an enzyme that is produced and released by activated neutrophils in response to an inflammatory stress $^{(8)}$ and plays a key role in the pathogenesis of CVD. Many of the morbidities of pregnancy such as pre-eclampsia and intra-uterine growth restriction exhibit increased systemic inflammatory responses, and it has been hypothesized that MPO plays an important role here as well ${ }^{(25)}$. Hung et $a l .{ }^{(8)}$ recently reported that higher MPO levels in maternal blood before delivery were associated with pre-eclampsia and intra-uterine growth restriction. However, in the current study no differences were seen in MPO activity. This is not surprising since the maternal blood sampling in the current study was in the first trimester, where there probably was no inflammatory stress, even though there appears to be oxidative stress.

The limitations of the present study are mainly the small sample sizes, the focus on only T1 and CB rather than all trimesters, and the lack of heterogeneity of the population studied. Although many more such studies on larger populations are required, the present study reprises the question regarding the prudency of a universal high-dose Fe supplementation in pregnant women with high $\mathrm{Hb}_{1}$. In conclusion, the study suggests that low PON-1 activity in the first trimester of pregnancy, particularly in women with high $\mathrm{Hb}_{1}$, could be an early indicator of oxidative stress, which could potentially have adverse effects on the fetus.

\section{Acknowledgements}

Acknowledgements: The authors would like to acknowledge Priyanka Bannikoppa for her help in sample retrieval and analysis and Dr Pratibha Dwarkanath for providing essential details regarding the cohort. Financial support: This research was funded by the Department of Biotechnology, Government of India (reference 102/IFD/ SAN/3325/2013-2014). The funder had no role in the design, analysis or writing of this article. Conflict of interest: None. Authorship: R.S.P., L.S., I.M. and A.V.K. were responsible for formulating the research question and designing the study. R.S.P., L.S. and I.M. were responsible for doing the sample analysis. T.T., L.S., I.M. and R.S.P. analysed the data and all authors contributed to the writing of the manuscript. Ethics of human subject participation: This study was conducted according to the guidelines laid down in the Declaration of Helsinki and all procedures involving human subjects/patients were approved by the Institutional Ethical Review Board of St. John's Medical College Hospital, Bangalore, India. Written informed consent was obtained from all participants at enrolment.

\section{References}

1. Ministry of Health and Family Welfare, Government of India (2013) Guidelines for the Control of Iron Deficiency Anaemia: A National Iron plus Initiative. New Delhi: Adolescent Division, Ministry of Health and Family Welfare.

2. Tiwari AKM, Mahdi AA, Chandyan S et al. (2011) Oral iron supplementation leads to oxidative imbalance in anemic women: a prospective study. Clin Nutr 30, 188-193.

3. Ziaei S, Norrozi M, Faghihzadeh S et al. (2007) A randomised placebo-controlled trial to determine the effect of iron supplementation on pregnancy outcome in pregnant women with haemoglobin $\geq 13.2 \mathrm{~g} / \mathrm{dl}$. BJOG 114, 684-688.

4. Burton GJ \& Jauniaux E (2011) Oxidative stress. Best Pract Res Clin Obstet Gynaecol 25, 287-299.

5. Weinberg ED (2009) Are iron supplements appropriate for iron replete pregnant women? Med Hypotheses 73, 714-715.

6. Shastri L, Mishra PE, Dwarkanath P et al. (2015) Association of oral iron supplementation with birth outcomes in nonanaemic South Indian pregnant women. Eur J Clin Nutr 69 , 609-613.

7. Mackness MI, Durrington PN, Ayub A et al. (1999) Low serum paraoxonase: a risk factor for atherosclerotic disease? Chem Biol Interact 119-120, 389-397.

8. Hung TH, Chen SF, Lo LM et al. (2012) Myeloperoxidase in the plasma and placenta of normal pregnant women and women with pregnancies complicated by preeclampsia and intrauterine growth restriction. Placenta 33, 294-303.

9. Dwarkanath P, Barzilay JR, Thomas T et al. (2013) High folate and low vitamin B-12 intakes during pregnancy are associated with small-for-gestational age infants in South Indian women: a prospective observational cohort study. Am J Clin Nutr 98, 1450-1458.

10. Genc H, Uzun H, Benian A et al. (2011) Evaluation of oxidative stress markers in first trimester for assessment of preeclampsia risk. Arch Gynecol Obstet 284, 1367-1373.

11. Burlina A, Michielin E \& Galzigna L (1977) Characteristics and behaviour of arylesterase in human serum and liver. Eur J Clin Invest 7, 17-20.

12. Gan KN, Smolen A, Eckerson HW et al. (1991) Purification of human serum paraoxonase/arylesterase. Evidence for one esterase catalyzing both activities. Drug Metab Dispos 19, 100-106.

13. Miller NJ, Rice-Evans C, Davies MJ et al. (1993) A novel method for measuring antioxidant capacity and its 
application to monitoring the antioxidant status in premature neonates. Clin Sci 84, 407-412.

14. Scanlon KS, Yip R, Schieve LA et al. (2000) High and low hemoglobin levels during pregnancy: differential risks for preterm birth and small for gestational age. Obstet Gynecol 96, 741-748.

15. Zhou LM, Yang WW, Hua JZ et al. (1998) Relation of hemoglobin measured at different times in pregnancy to preterm birth and low birth weight in Shanghai, China. Am J Epidemiol 148, 998-1006.

16. Ribot B, Aranda N, Giralt M et al. (2013) Effect of different doses of iron supplementation during pregnancy on maternal and infant health. Ann Hematol 92, 221-229.

17. Beard JL (2000) Effectiveness and strategies of iron supplementation during pregnancy. Am J Clin Nutr 71, 5 Suppl., 1288S-1294S.

18. Kamp F \& Donangelo CM (2008) Supplementing young women with both zinc and iron protects zinc-related antioxidant indicators previously impaired by iron supplementation. J Nutr 138, 2186-2189.

19. Lachili B, Hininger I, Faure $\mathrm{H}$ et al. (2001) Increased lipid peroxidation in pregnant women after iron and vitamin C supplementation. Biol Trace Elem Res 83, 103-110.

20. Bhatla N, Kaul N, Lal N et al. (2009) Comparison of effect of daily versus weekly iron supplementation during pregnancy on lipid peroxidation. J Obstet Gynaecol Res 35, 438-445.

21. Gelisgen R, Genc H, Kayali R et al. (2011) Protein oxidation markers in women with and without gestational diabetes mellitus: a possible relation with paraoxonase activity. Diabetes Res Clin Pract 94, 404-409.

22. La Du BN, Aviram M \& Billecke S (1999) On the physiological role(s) of the paraoxonases. Chem Biol Interact 119, 379-388.

23. Mogarekar MR \& Rojekar MV (2014) Harbingers of neonatal birth weight: the PON1 arylesterase and lactonase activities. Turk J Biochem 39, 25-29.

24. Vlachos GD, Bartzeliotou A, Schulpis KH et al. (2006) Maternal-neonatal serum paraoxonase 1 activity in relation to the mode of delivery. Clin Biochem 39, 923-928.

25. Gandley RE, Rohland J, Zhou Y et al. (2008) Increased myeloperoxidase in the placenta and circulation of women with preeclampsia. Hypertension 52, 387e93. 